\title{
Anti-inflammatory Activity of Nigella sativa oil Mediated Silver Nanoparticles
}

\author{
Sheik Shehensha ${ }^{1, *}$, M.Vijaya Jyothi ${ }^{2}$
}

\section{Sheik Shehensha ${ }^{1, *}$, M.Vijaya} Jyothi ${ }^{2}$

${ }^{\prime}$ Research Scholar, Pharmaceutical Sciences, Jawaharlal Nehru Technological University Anantapur, Anantapuramu. Andhra Pradesh, INDIA.

2Professor, Department of Pharm. Chemistry, Raghavendra Institute of Pharmaceutical Education and Research, Anantapuramu, Andhra Pradesh, INDIA.

\section{Correspondence}

\section{Sheik Shehensha}

Research Scholar, Pharmaceutical

Sciences, Jawaharlal Nehru Technological University Anantapur, Anantapuramu.

Andhra Pradesh, INDIA.

Phone no: 9959856721

E-mail: shahenshah7@gmail.com

History

- Submission Date: 02-04-2020;

- Review completed: 05-05-2020;

- Accepted Date: 03-06-2020

DOI : 10.5530/pj.2020.12.153

Article Available online

http://www.phcogj.com/v12/i5

\section{Copyright}

(c) 2020 Phcogi.Com. This is an openaccess article distributed under the terms of the Creative Commons Attribution 4.0 International license.

\begin{abstract}
Aim: The aim of the study was to employ Nigella sativa oil in the synthesis of silver nanoparticles and to assess the anti-inflammatory activity of the Nigella sativa oil mediated silver nanoparticles. Background: The introduction of Nanoparticles (NPs) has transFigured many fields like medicine, nutrition and electronics. The usage of nanotechnology in medicine particularly for drug delivery is revealed to have numerous benefits. Nanoparticles are being used to decrease toxicity and side effects that drugs may impose to the patient. Nigella sativa is considered as a miracle seed. It has been reported to have anti-inflammatory, diuretic, and antihypertensive activity. Plant mediated biological synthesis of nanoparticles is simple and eco-friendly method. This work therefore was aimed to synthesize Nigella sativa oil mediated silver nanoparticles and evaluate its anti-inflammatory activity. Materials and Methods: Nigella sativa oil mediated silver nanoparticles were synthesised by short term (1 day) interaction of Nigella sativa seed extract $(1 \mathrm{ml})$ with $2 \mathrm{mM} \mathrm{AgNO}_{3}$ solution and centrifuged to obtain silver nanoparticles. The nanoparticles were characterised by UV-Visible spectrophotometer, FTIR and Scanning Electron Microscopy (SEM). Further the oil mediated AgNPs were evaluated for anti-inflammatory activity by in vitro and in vivo methods. Results: Nigella sativa oil mediated AgNPs were biofabricated with ease and exhibited good anti-inflammatory activity compared to standard. Conclusion: This study concludes that Nigella sativa seed oil mediated silver nanoparticles have the potential to be used as an effective antioxidant. Hence, it may be used in many medicinal applications to treat inflammation.

Key words: Nigella sativa, Rananculaceae, Silver nanoparticles, SEM analysis, AntiInflammatory effect.
\end{abstract}

\section{INTRODUCTION}

Noble metals, such as silver and gold, due to their specific and unique chemical, biological, and physical properties have attained tremendous interest in nanomedicine. ${ }^{1}$ The phytochemical synthesis of silver nanoparticles (SNPs) by plants or seed extracts has unique role in the field of nanotechnology and nanomedicine as it provides alternative therapeutic options. Several studies revealed that SNPs possess considerable inhibitory effect against microorganisms and possess free radical scavenging and anti- inflammatory properties. $^{2}$ Few studies reported that silver nanoparticles exerts cytotoxic, pro-inflammatory and pro-apoptotic effects mediated via reactive oxygen species (ROS) produced in normal and cancer cell lines. Prostaglandins (PGs) are effective proinflammatory mediators attained from arachidonic acid metabolism by cyclooxygenases and play an important role in modulating a number of pathophysiological conditions like inflammation and allergic immune responses. ${ }^{3}$

The role of herbal medications to boost common health conditions is always considered effective. ${ }^{4}$ Herbal therapies are often used to treat inflammation, although their molecular and cellular bases of action are less elucidated. Nigella sativa (black cumin) seed is used in customary medicine in various Middle Eastern and Asian countries to treat several diseases ${ }^{5}$. Thymoquinone (2-isopropyl-5-methyl-1,4-benzoquinone) is the most copious phytoconstituent of the seed extract and possess antioxidant and anti-inflammatory activities. $^{6}$

Although steroids and non-steroidal antiinflammatory drugs (NSAIDs) are extensively used to treat inflammation, their side effects are undesirable. Therefore, the development of new materials with comparable results and fewer side effects is needed.? The purpose of our study is to synthesize silver nanoparticles using ethanolic seed extracts of Nigella sativa, to characterize them and to evaluate their biological activity by studying inhibition of albumin denaturation and carrageenan-induced paw edema in Wistar rats.

\section{MATERIAL AND METHODS}

\section{Collection and authentication of plant part}

Nigella sativa seeds were purchased from local market, Ananthapuramu, India, authenticated with voucher no. 0861 . The seeds were blended into fine powder. The powder was stored in well closed air tight container for further use.

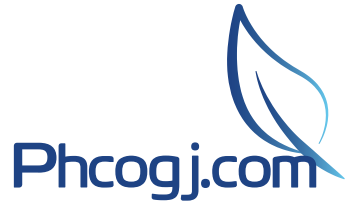

Cite this article: Shehensha S, Jyothi MV. Anti-inflammatory Activity of Nigella sativa oil Mediated Silver Nanoparticles. Pharmacogn J. 2020;12(5):1086-92. 


\section{Chemicals and reagents}

Silver nitrate $\left(\mathrm{AgNO}_{3}\right)$, Bovine serum albumin was purchased from Sigma Aldrich, India. All other chemicals used are of analytical grade. Throughout the experiment double distilled water was used.

\section{Preparation of plant material}

The powdered material was macerated in $200 \mathrm{ml}$ of ethanol, for 72 hours with occasional stirring. The extract was filtered by whatmann filter paper. The extract was concentrated under vacuum using rotaevaporator. Oily substance was procured after evaporation of the solvents from extract. The extract was stored in refrigerator.

\section{Biosynthesis of Silver nanoparticles (SNPs)}

One $\mathrm{ml}$ of extract (ethanol) was added to $10 \mathrm{ml}$ of $2 \mathrm{mM} \mathrm{AgNO}_{3}$ solution, in a $50 \mathrm{ml}$ beaker. The preparation was kept in dark, overnight at room temperature. The obtained nanoparticles were centrifuged at $10,000 \mathrm{rpm}$ for 20 minutes. ${ }^{8}$ The solution was filtered by whatmann filter paper and kept in refrigerator for future use.

\section{Characterization of nanoparticles}

To check the formation of AgNPs in the extract, absorption studies of developed nanoparticles were measured by UV-visible spectrophotometer (LAB INDIA, UV-3092) for nanoparticles solution in the wavelength range $200-800 \mathrm{~nm}$. The synthesized AgNPs chemical composition was studied by using FTIR spectrometer. FTIR graphs were taken for ethanolic seed extracts of Nigella sativa and for the AgNPs prepared from seed extract, to identify the functional groups. The Size dispersal of the prepared nanoparticles and zeta potential was determined by Zetasizer (Horiba SZ-100). The detailed morphology of nanoparticles was confirmed through Scanning Electron Microscopic (SEM) images.

\section{UV-Visible spectroscopy}

Reduction of AgNPs on exposure to seed extract can be detected by color change. The color change from pale yellow to brown was observed when the seed extracts containing silver nitrate solution was kept for overnight. It may be due to addition of aqueous $\mathrm{AgNO}_{3}$ solution into seed extract, that the $\mathrm{Ag}^{+}$ions were attracted by the -O- group of biomolecules to form silver complex then reduced to $\mathrm{Ag}^{0}$. However deviations in both $\mathrm{AgNO}_{3}$ and seed extract confirmed that formation of NPs with the optimized concentrations exhibited superior plasmon resonance absorbance at $420 \mathrm{~nm}$, as shown in Figure 1.

\section{FTIR analysis}

FTIR graph indicates that the absorption bands at $3347(\mathrm{O}-\mathrm{H}$ stretching, $\mathrm{H}$-bonds of alcohols, phenols and $\mathrm{N}-\mathrm{H}$ stretching due to primary, secondary amines and amides), 2927 and 2858 (C-H stretching of alkanes). The $-\mathrm{C}=\mathrm{C}$ - stretching and $\mathrm{N}-\mathrm{H}$ bending of alkenes and primary amines is evident at $1650 \mathrm{~cm}^{-1}$. C-C stretching of aromatics at $1459 \mathrm{~cm}^{-1}$ and $\mathrm{C}-\mathrm{O}$ stretching of alcohols, carboxylic acids, esters, ethers and $\mathrm{C}-\mathrm{N}$ stretching of aliphatic amines at $1105 \mathrm{~cm}^{-1}$. The prepared silver nanoparticles showed shift of absorption bands from 3386 to 3348,2922 to 2912 and 1642 to $1651 \mathrm{~cm}^{-1}, 1442$ to $1401 \mathrm{~cm}^{-1}$ after bioreduction. The FTIR of Nigella sativa ethanolic seed extract and ethanolic based nanoparticles is shown in Figures 2 and 3 respectively. The vibrational bands analogous to bonds such as $-\mathrm{C}=\mathrm{C}-\&-\mathrm{C}=\mathrm{O}$ are attained from the compounds like flavonoids and alkaloids present in Nigella sativa seeds. So, it is presumed that the biomolecules and few proteins play a key role in capping, stabilization and reduction of $\mathrm{Ag}^{+}$ to SNPs.

\section{Particle size and Zeta potential}

The particle size and Zeta potential of the prepared nanoparticles was assessed by using Zetasizer (Horiba SZ-100 Ver 2.20). The size dispersal of the nanoparticles was measured employing Dynamic Light Scattering (DLS). For AgNPs prepared from Nigella sativa ethanol extract, DLS analysis showed nanoparticles with an average diameter of $157 \mathrm{~nm}$, with a Poly-dispersity Index (PdI) of 0.309, as shown in Figure 4 . The zeta potential of dispersion refers to the electrostatic voltage at the shear layer of a nanoparticle. In this AgNPs system, the zeta potential for AgNPs prepared from Nigella sativa ethanol extract was $-8.9 \mathrm{mV}$, as shown in Figure 5.

A colloid system is considered electrostatically stable when its zeta potential values are in range of $+30 \mathrm{mV}$ to $-30 \mathrm{mV}$. The stabilization of nanoparticles is due to electrostatic interactions and steric hindrance, which prevent the coalescence and aggregation of the nanoparticles.

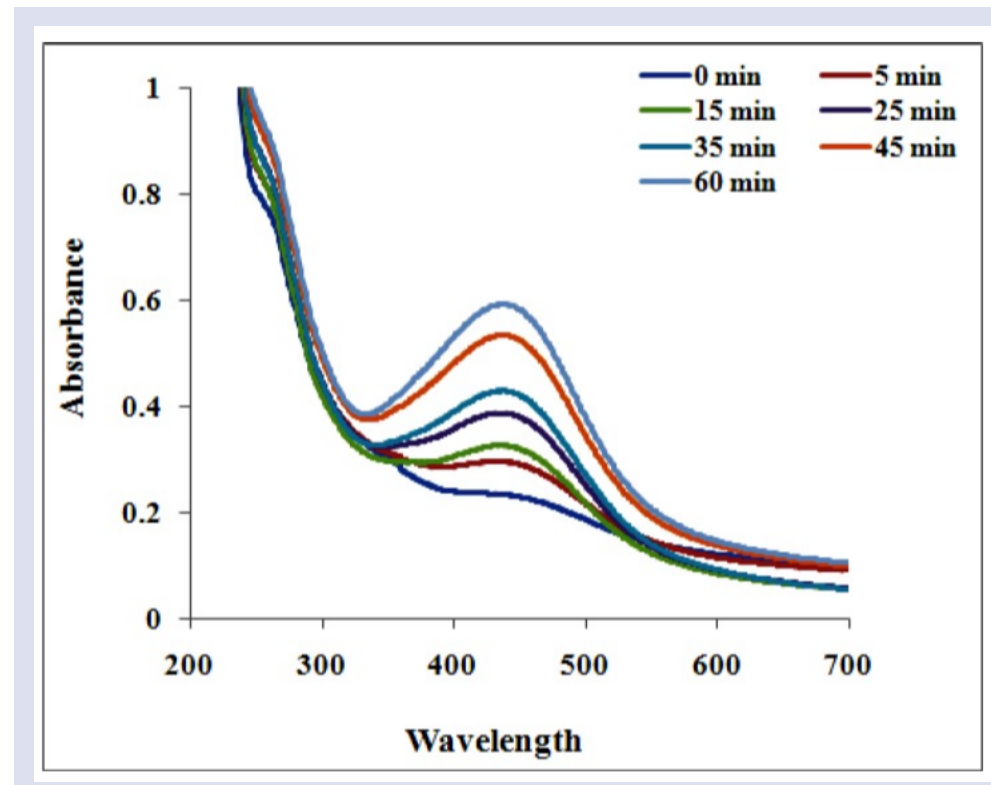

Figure 1: UV -Visible spectra of Nigella sativa silver nanoparticles. 


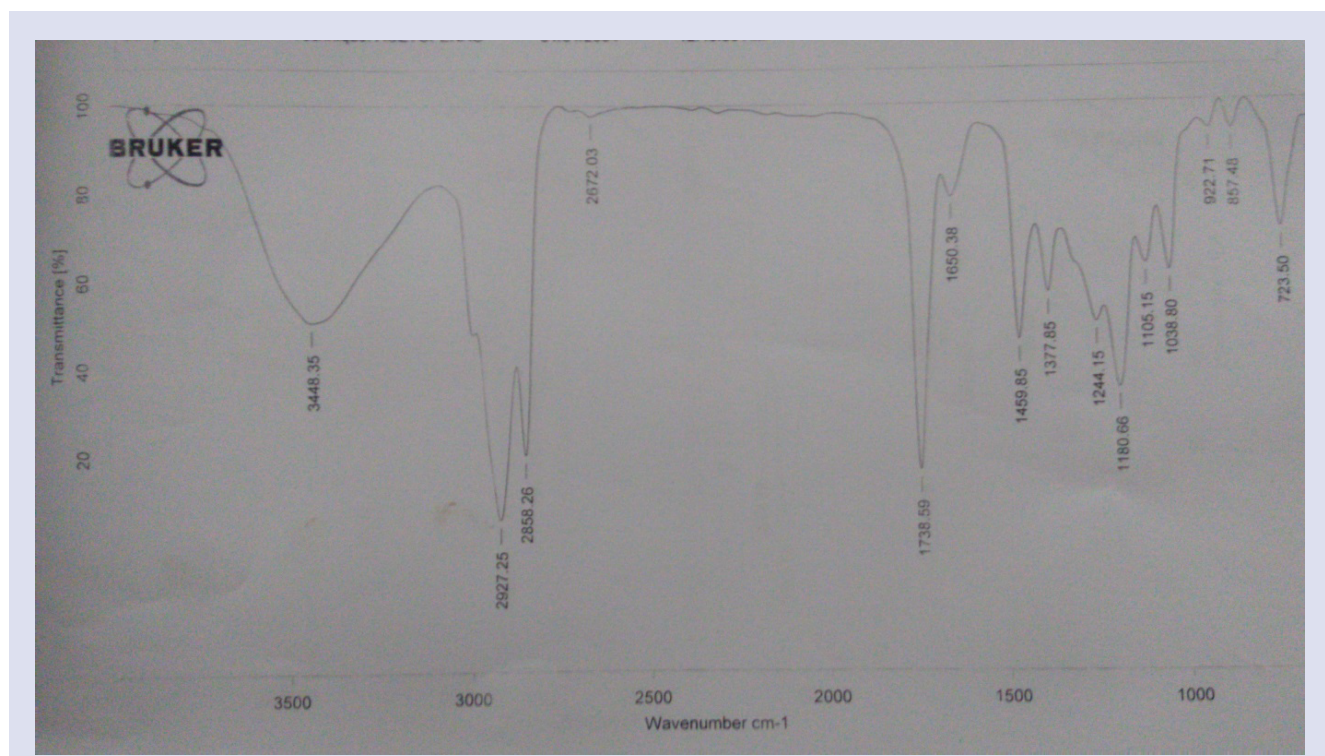

Figure 2: FT-IR spectra of Nigella sativa seed extract (ethanol).

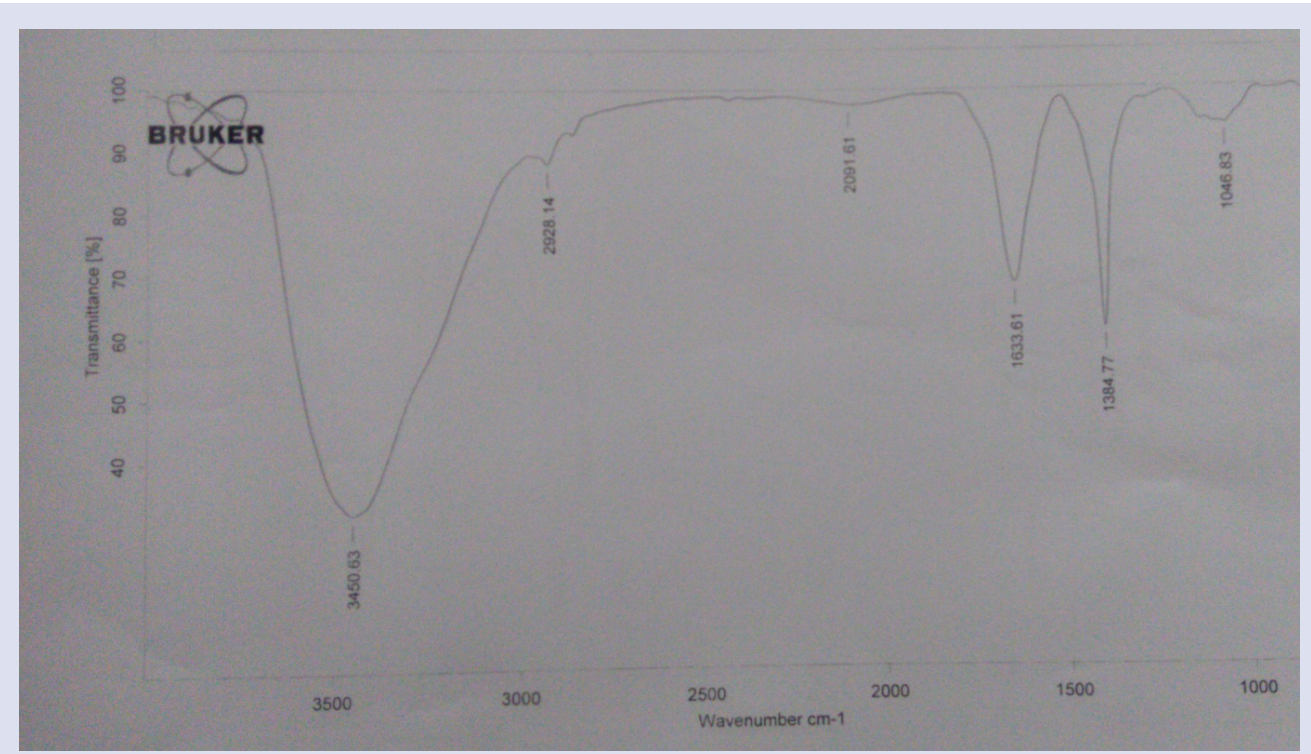

Figure 3: FT-IR spectra of Nigella sativa seed extract (ethanol) based silver nanoparticles.

\section{SEM analysis}

Scanning Electron Microscopy established morphology and size of Silver nanoparticles. The experimental result showed that the diameter of the prepared nanoparticle (ethanol extract) with an average size of about $157 \mathrm{~nm}$ as shown in Figure 6.

\section{ANTI-INFLAMMATORY ACTIVITY}

\section{In vitro anti-inflammatory activity}

The biosynthesized compounds were evaluated for in vitro antiinflammatory activity by using inhibition of albumin denaturation method $^{8}$. The reaction mixture comprises test extracts and $1 \%$ aqueous solution of bovine albumin fraction. The $\mathrm{pH}$ of the reaction mixture was regulated using diluted $\mathrm{HCl}$. The sample extracts were incubated at $38^{\circ} \mathrm{C}$ for $20 \mathrm{~min}$ and later heated to $51^{\circ} \mathrm{C}$ for $20 \mathrm{~min}$. The samples were cooled and turbidity was quantified spectrophotometrically at 660 $\mathrm{nm}$, shown in Table 1 and Figure 7. The measurements were performed in triad. Percent inhibition of protein denaturation was calculated as follows:

$\%$ Inhibition $=[$ Acontrol - Asample $/$ Acontrol $] \times 100$

where Acontrol is absorbance of solution without extract, Asample is absorbance of solution with sample extract/standard.

\section{In vivo anti-inflammatory activity}

The In vivo Anti-inflammatory activity of biosynthesized silver nanoparticles was assessed by carrageenan-induced inflammation in male Wistar rats (120-180 g). ${ }^{9}$ The procedures for invivo experiments were approved by IAEC, protocol number-IAEC/XII/02/RIPER/2018. The animals were procured from Sree Raghavendra Enterprises, Bengaluru and were adapted for a week under the following conditions: 12-h light/12-h dark cycle unconfined to water and fed by a normal caloric standard diet. The rats were deprived of water during experiment to reduce variability in edematous response. Paw edema was induced in 


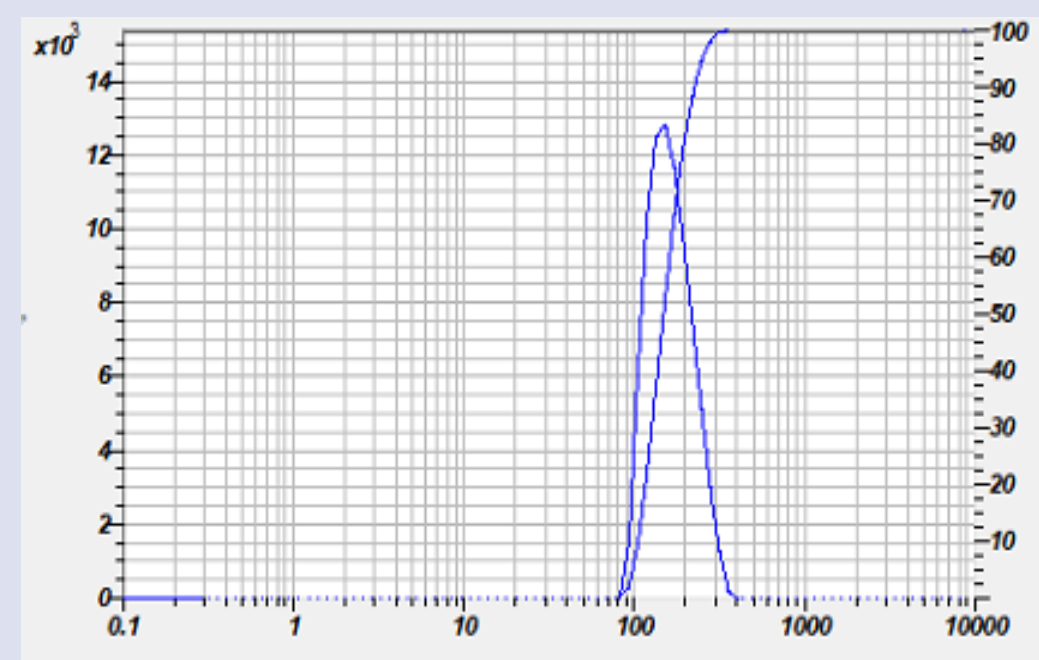

Figure 4: Size distribution of Nigella sativa silver nanoparticles Ethanolic extract.

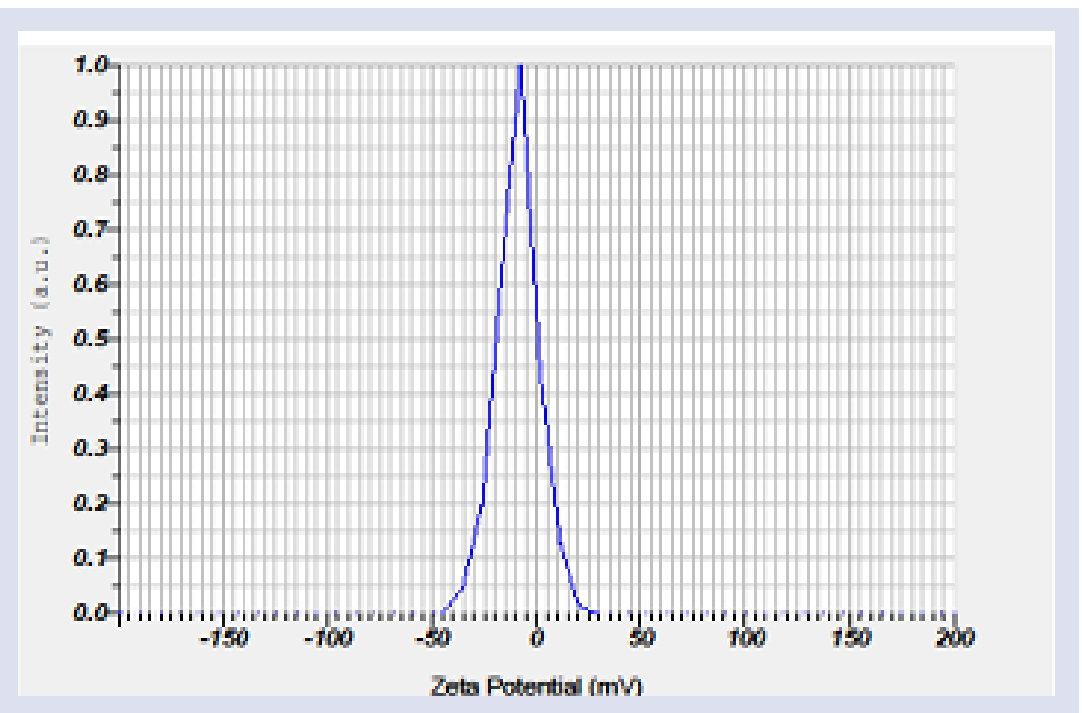

Figure 5: Zeta Potential of Nigella sativa silver nanoparticles Ethanolic extract.

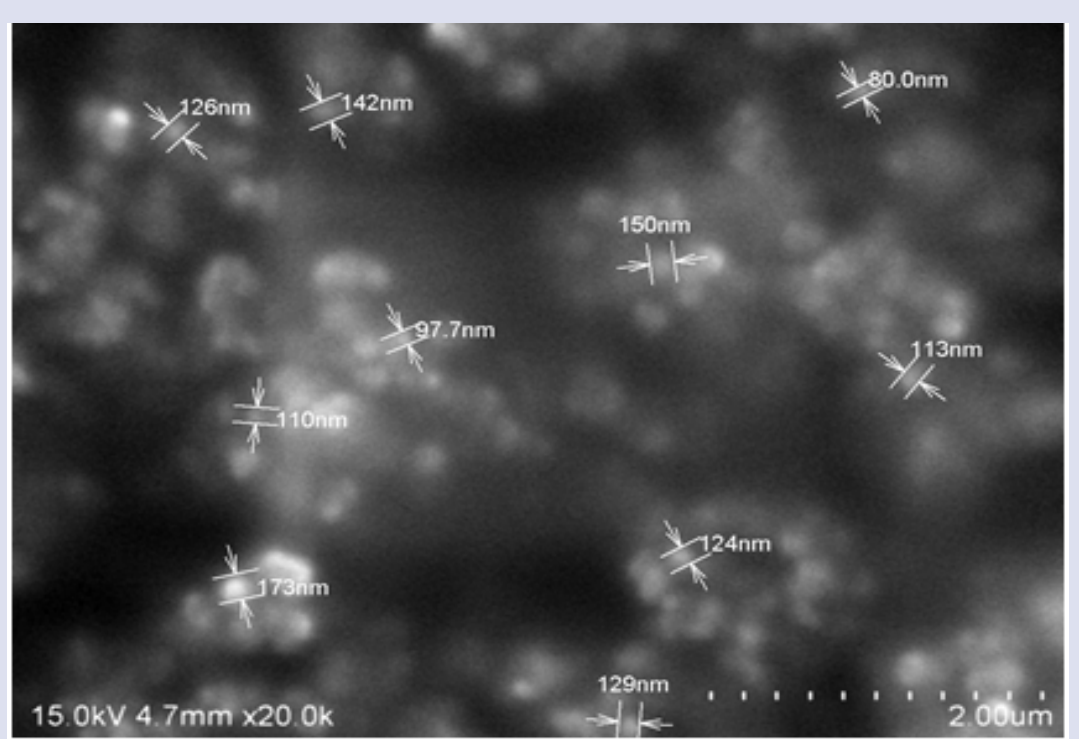

Figure 6: SEM image of Nigella sativa- ethanol silver nanoparticles. 
male Wistar rats (110-130 g, 3 months old) by the injection of $0.1 \mathrm{ml}$ $1 \%$ carrageenan in normal saline in the right hind foot pad. ${ }^{7}$ The left hind foot pad was injected with same volume of saline solution. The plant extract was given orally at a dose of $500 \mathrm{mg} / \mathrm{Kg}$, prior to injection of carrageenan. Animals were separated into five groups of six animals each: group 1 is considered as control, group 2 (positive control group) was treated with Indomethacin $(10 \mathrm{mg} / \mathrm{b} . \mathrm{w} \text {. I.P })^{8}$, group 3 pre-treated with carrageenan (sub-plantar); group 4 pre-treated with $500 \mathrm{mg} / \mathrm{b} . \mathrm{w}$. Nigella sativa seed extract; group 5 was pre-treated with AgNPs 0.3 $\mathrm{mg} / \mathrm{b} . \mathrm{w}(0.19 \mathrm{mg} / \mathrm{mL})$. Rat paw edema was determined by the volume displacement method (Plethysmometer) before the administration of the substances and at $30 \mathrm{~min}, 1,2,3,4$ and $5 \mathrm{~h}$, after carrageenan injection, shown in Table 2. Anti-inflammatory activity was evaluated for each animal in comparison with control and calculated using the formula:

$I \%=[(1(\mathrm{dt} / \mathrm{dc})] 100$

Where $\mathrm{dt}$ is variance in paw volume in drug treated group and $\mathrm{dc}$ is variance in paw volume in control group.

\section{Statistical analysis}

Results are expressed as mean \pm SEM. The difference between treated groups and control group was compared using one-way Anova, followed by Dennett's post hoc test. The analysis was carried out using software PRISMA (version 8.1, Graphpad software). P values $<0.05$ were considered significant.

\section{RESULTS AND DISCUSSION}

The present study revealed concentration dependent inhibition of protein (Bovine serum albumin) denaturation by ethanolic seed extract of Nigella sativa and AgNPs. The lowest activity of seed extract, AgNPs and Indomethacin was seen at a concentration of $100 \mu \mathrm{g} / \mathrm{ml}$ and the highest activity was seen at $500 \mu \mathrm{g} / \mathrm{ml}$. The significant effect of AgNPs was found near to that of standard Indomethacin at $500 \mu \mathrm{g} / \mathrm{ml}$, as shown in table 1. The present investigation shows that the AgNPs exhibited significant anti-inflammatory activity like that of standard against protein denaturation. The synthesized AgNPs effectively inhibited thermally induced albumin denaturation at tested concentrations,

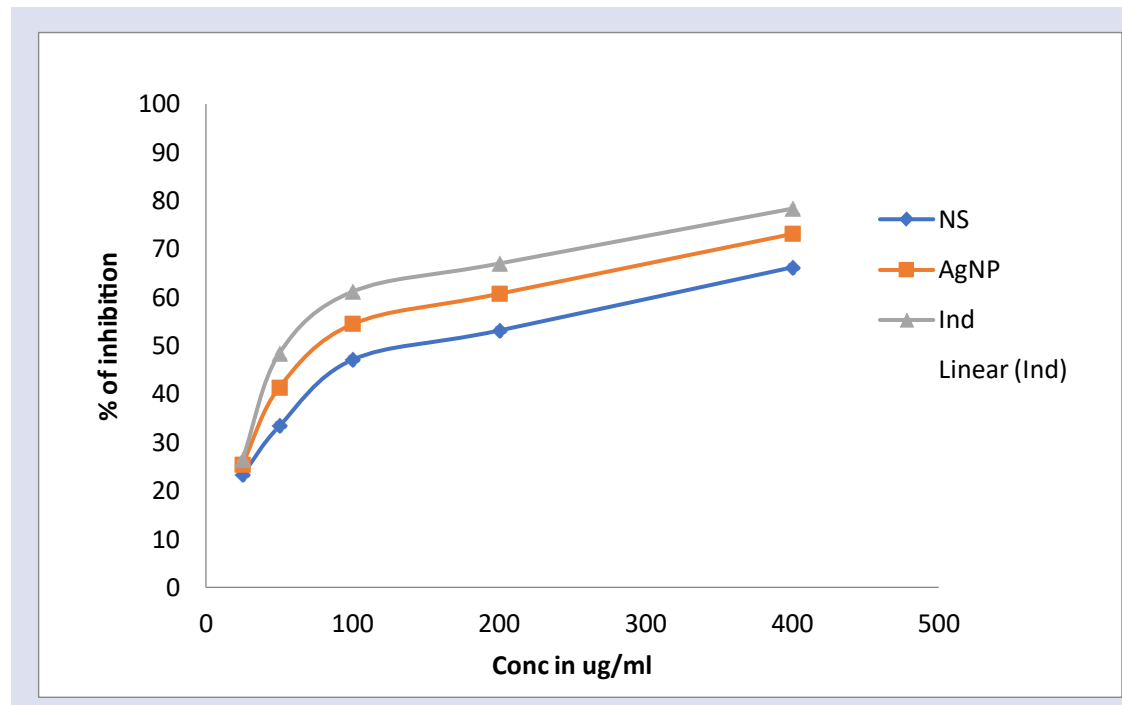

Figure 7: Percent inhibition of protein denaturation.

Table 1: Effect of Nigella sativa, Silver nanoparticles and Indomethacin on Protein denaturation (Bovine serum albumin).

\begin{tabular}{cccc}
\hline \multirow{2}{*}{ Concentration } & Nigella sativa & \% of inhibition & Indomethacin (std) \\
\cline { 2 - 4 } & $23.40 \pm 1.50$ & $25.61 \pm 1.45$ & $26.55 \pm 1.51$ \\
$200 \mu \mathrm{g} / \mathrm{ml}$ & $33.41 \pm 1.89$ & $41.42 \pm 1.72$ & $48.42 \pm 2.10$ \\
$300 \mu \mathrm{g} / \mathrm{ml}$ & $47.12 \pm 2.40$ & $57.48 \pm 2.11$ & $61.23 \pm 2.89$ \\
$400 \mu \mathrm{g} / \mathrm{ml}$ & $53.15 \pm 2.85$ & $65.75 \pm 2.89$ & $67.05 \pm 3.11$ \\
$500 \mu \mathrm{g} / \mathrm{ml}$ & $66.15 \pm 3.62$ & $76.11 \pm 3.12$ & $78.41 \pm 3.66$ \\
$\mathrm{IC}_{50} \mu \mathrm{g} / \mathrm{ml}$ & 310.45 & 261.78 & 255.42 \\
\hline
\end{tabular}

Table 2: Values are expressed as means $\pm S E M$ in each group $(n=5) ;{ }^{*} P<0.05,{ }^{* *} P<0.01,{ }^{* * *} P<0.001$ compared with the control; values in parenthesis represent the percentage of inhibition. Abbreviation: N.S- Nigella sativa, SNPs- silver nanoparticles.

\begin{tabular}{|c|c|c|c|c|c|c|c|}
\hline \multirow{2}{*}{ Treatment } & \multirow{2}{*}{ Dose $(\mathrm{mg} / \mathrm{kg})$} & \multicolumn{6}{|c|}{ Edema (mL) } \\
\hline & & $30 \mathrm{~min}$ & $1 \mathrm{hr}$ & $2 \mathrm{hr}$ & $3 \mathrm{hr}$ & $4 \mathrm{hr}$ & $5 \mathrm{hr}$ \\
\hline Control & --- & $0.26 \pm 0.06$ & $0.29 \pm 0.05$ & $0.31 \pm 0.05$ & $0.38 \pm 0.05$ & $0.36 \pm 0.06$ & $0.35 \pm 0.05$ \\
\hline Indomethacin & 10 & $0.22 \pm 0.04(25.50)$ & $0.18 \pm 0.04(43.80)$ & $\begin{array}{c}0.20 \pm 0.04^{* *} \\
(49.50)\end{array}$ & $\begin{array}{l}0.12 \pm 0.04^{* * *} \\
\quad(68.60)\end{array}$ & $\begin{array}{c}0.10 \pm \\
0.02^{* * \star}(71.50)\end{array}$ & $0.21 \pm 0.06(17.80)$ \\
\hline N.S & 500 & $0.24 \pm 0.02$ & $0.20 \pm 0.03$ & $0.18 \pm 0.02$ & $0.15 \pm 0.02$ & $.0 .16 \pm 0.03$ & $0.19 \pm 0.05$ \\
\hline SNP & 0.3 & $\begin{array}{c}0.20 \pm 0.01^{*} \\
(54.40)\end{array}$ & $\begin{array}{c}0.17 \pm 0.01^{*} \\
(45.60)\end{array}$ & $\begin{array}{c}0.19 \pm 0.02^{* *} \\
(50.50)\end{array}$ & $\begin{array}{c}0.16 \pm 0.01^{* * *} \\
(55.70)\end{array}$ & $\begin{array}{c}0.14 \pm \\
0.04^{* * *}(60.50)\end{array}$ & $0.17 \pm 0.02(35.70)$ \\
\hline
\end{tabular}


showing their ability to control protein denaturation involved in the inflammatory process.

Carrageenan-induced edema in the rear foot pad was used as an exemplary to evaluate the temporal associations between edema development and the release of cytokines ${ }^{10}$. Paw injection of carrageenan exhibited a significant increase in swelling, with a maximum at $2 \mathrm{~h}$ after administration. The extract obtained from the seeds of Nigella sativa exerted anti-inflammatory effect at the administered dose $(p>0.05)$. The orally administered AgNPs showed a substantial inhibition of rat paw edema when compared to that of control group. The maximum inhibition percentages were observed as $54.40 \%$ ( 1 hour) and $60.30 \%$ (5 hours) at dose of $0.3 \mathrm{mg} / \mathrm{kg}$ (body weight). Standard drug, Indomethacin showed significant inhibition $(P<0.001)$ of paw edema, by $71.20 \%$ at 5 hours.

Carrageenan-induced rat paw edema exemplary in rats inhibits the enzyme cyclo-oxygenase and is used to assess nonsteroidal antiinflammatory effect, which primarily inhibits the enzyme CoX involved in prostaglandin synthesis. ${ }^{11}$ The Nigella sativa seed extracts were investigated for anti-inflammatory and analgesic actions in animal models. The anti-inflammatory activity of the alcoholic extracts of Nigella sativa seeds with due to their Thymoquinone (TQ) content was reported. ${ }^{12}$ TQ reduces proinflammatory lipid intermediaries by hindering eicosanoid generation in vitro. Therefore, the inhibitory activity of AgNPs can be attributed to the nanostructure and may be due to inhibition of the cyclooxygenase leading to inhibition of prostaglandin synthesis.

The results suggested that nanoparticles loaded with silver might interfere with release of acute inflammatory mediators and antagonize their action. ${ }^{13}$ The innate anti-inflammatory activity may be due to increased penetrability and retention property of AgNPs in the edema region. ${ }^{14,15}$

\section{CONCLUSION}

Ethanolic seed extract of Nigella sativa was used as reducing agent for the green synthesis of SNPs. The bio-synthesized nanoparticles were confirmed by analytical characterization techniques. In vivo anti-inflammatory activity of plant-based silver nanoparticles is less explored. The synthesized nanoparticles exhibited promising antiinflammatory effect, examined both in vitro and in vivo. The in vitro antiinflammatory effect was tested by Bovine serum albumin denaturation method, where the biosynthesized nanoparticles exhibited significant activity. Invivo anti-inflammatory activity of the AgNPs showed that the biosynthesized nanoparticles showed significant activity at minimal dose $(0.3 \mathrm{mg} / \mathrm{kg})$. Thus, albumin denaturation and edema inhibition activities of silver nanoparticles from Nigella sativa extract clearly establish their anti-inflammatory potential and therefore could be considered as potential source of the anti-inflammatory drug.

\section{ACKNOWLEDGEMENTS}

The authors thank the Principal, Vice-Principal, Director R\&D, RERDS- Raghavendra Institute of Pharmaceutical Education and
Research for providing necessary facilities and assistance to carry out the research work.

\section{CONFLICTS OF INTEREST}

All the authors disclose no conflicts of interest.

\section{REFERENCES}

1. Burdușel AC, Gherasim O, Grumezescu AM, Mogoantă L, Ficai A, Andronescu E. Biomedical applications of silver nanoparticles: An up-to-date overview. Nanomaterials. 2018;8(9):681.

2. Guntur SR, Kumar NS, Hegde MM, Dirisala VR. In vitro studies of the antimicrobial and free-radical scavenging potentials of silver nanoparticles biosynthesized from the extract of Desmostachya bipinnata. Analytical Chemistry Insights. 2018;13:1-9.

3. El Mezayen R, El Gazzar M, Nicolls MR, Marecki JC, Dreskin SC, Nomiyama $\mathrm{H}$. Effect of thymoquinone on cyclooxygenase expression and prostaglandin production in a mouse model of allergic airway inflammation. Immunology Letters. 2006;106(1):72-81.

4. Sater KA, Shalaby A, Abdel-Hamid GE, Hassan AM, El-Deen as. Hepatorenal changes by Nigella sativa seeds powder in diabetic rats. Pakistan Journal of Physiology. 2016;12(2):3-7.

5. Chehl N, Chipitsyna G, Gong Q, Yeo CJ, Arafat HA. Anti-inflammatory effects of the Nigella sativa seed extract, thymoquinone, in pancreatic cancer cells. HPB. 2009;11(5):373-81.

6. Ong CK, Lirk P, Tan CH, Seymour RA. An evidence-based update on nonsteroidal anti-inflammatory drugs. Clinical Medicine \& Research. 2007;5(1):19-34.

7. Begum N, MH MI, Mathew S, Govindaraju A, Qadri I. Green synthesis, antioxidant potential and hypoglycemic effect of silver nanoparticles using Ethanolic leaf extract of Clausena anisata (Willd.) Hook. F. Ex Benth. of Rutaceae. Pharmacognosy Journal. 2016;8(6).

8. Ali SS, Kenawy ER, Sonbol FI, Sun J, Al-Etewy M, Ali A, Huizi L, El-Zawawy NA. Pharmaceutical potential of a novel chitosan derivative Schiff base with special reference to antibacterial, anti-biofilm, antioxidant, anti-inflammatory, hemocompatibility and cytotoxic activities. Pharmaceutical Research. 2019;36(1):5

9. Vijayaraj R, Kumar KN, Mani P, Senthil J, Kumar GD, Jayaseelan T. Green synthesis of silver nanoparticles from ethanolic seed extract of Acranythes aspera (Linn.) and its anti- inflammatory activities. Int J Pharm Ther. 2016;7:428.

10. Ghannadi A, Hajhashemi V, Jafarabadi $H$. An investigation of the analgesic and anti-inflammatory effects of Nigella sativa seed polyphenols. Journal of Medicinal food. 2005;8(4):488-93.

11. Taketo MM. Cyclooxygenase-2 inhibitors in tumorigenesis (Part II). Journal of the National Cancer Institute. 1998;90(21):1609-20.

12. David L, Moldovan B, Vulcu A, Olenic L, Perde-Schrepler M, Fischer-Fodor E, et al. Green synthesis, characterization and anti-inflammatory activity of silver nanoparticles using European black elderberry fruits extract. Colloids and Surfaces B: Biointerfaces. 2014;122:767-77.

13. Hajhashemi $V$, Ghannadi A, Heidari AH. Anti-inflammatory and wound healing activities of Aloe littoralis in rats. Research in Pharmaceutical Sciences. $2012 ; 7(2): 73$

14. Wong KK, Liu X. Silver nanoparticles-the real "silver bullet" in clinical medicine? Med Chem Comm. 2010;1(2):125-31.

15. Manikandan R, Manikandan B, Raman T, Arunagirinathan K, Prabhu NM, Basu MJ, et al. Biosynthesis of silver nanoparticles using ethanolic petals extract of Rosa indica and characterization of its antibacterial, anticancer and anti-inflammatory activities. Spectrochimica Acta Part A: Molecular and Biomolecular Spectroscopy. 2015;138:120-9. 


\section{GRAPHICAL ABSTRACT}

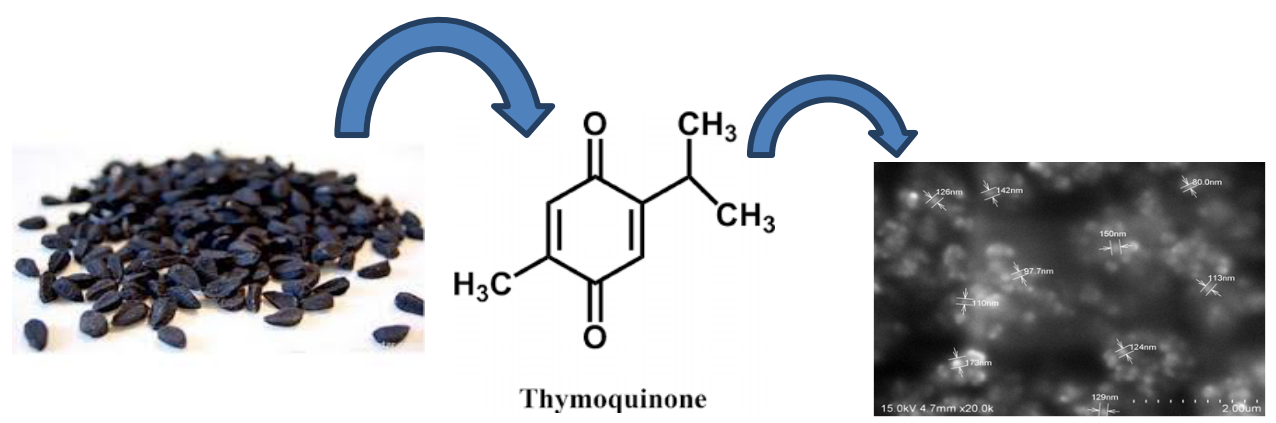

Nigella sativa seeds

SEM image of seed based silver nanoparticles
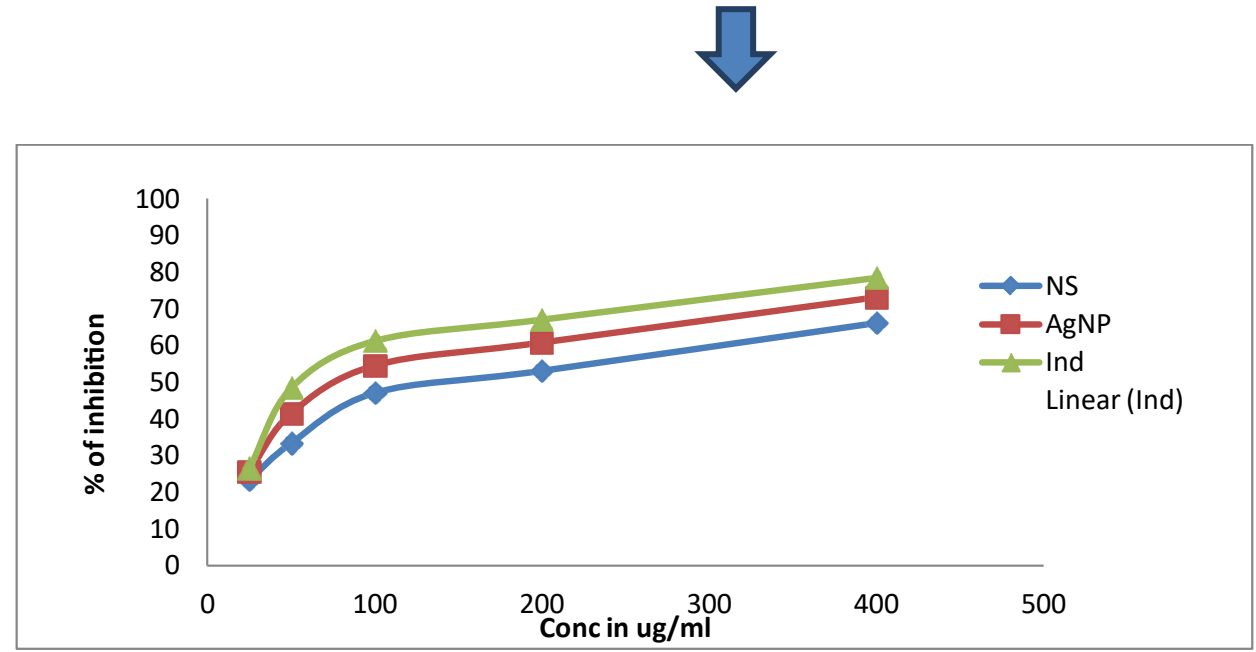

In vitro anti-inflammatory activity

\section{ABOUT AUTHORS}

\section{- S. SHEHENSHA}

Research Scholar, Dept. of Pharmaceutical Sciences, Jawaharlal Nehru Technological University Anantapur (JNTUA), Ananthapuramu, Andhra Pradesh, India. Pursuing Full-time Ph.D in JNTUA. Areas of interest- Nontechnology.

\section{- Dr.M. Vijaya Jyothi}

Professor and HoD, Co-Ordinator of PG programs, Raghavendra Institute of Pharmaceutical Education and Research (RIPER)Autonomous, Anantapur, Andhra Pradesh, India. In-charge, Head of the Department of Pharmaceutical chemistry, RIPERAutonomous, Anantapur, Andhra Pradesh, India - 522 721, (Affiliated to JNT University Anantapur (JNTUA), Andhra Pradesh, India, from Feb 2005 to till date.(ratified position by University).

\section{Research experience}

- Recipient of UGC Minor research grant for the year 2016-18

- RP-HPLC method was performed for more than 20 drugs

Cite this article: Shehensha S, Jyothi MV. Anti-inflammatory Activity of Nigella sativa oil Mediated Silver Nanoparticles. Pharmacogn J. 2020;12(5):1086-92. 